\title{
Explaining interviewer effects and respondent behavior: Theoretical models and empirical analysis*
}

\author{
JOST REINECKE ${ }^{1} \&$ PETER SCHMIDT ${ }^{2}$ \\ ${ }^{1}$ Institute of Sociology, University of Münster, Germany; ${ }^{2}$ Institute of Political Science, \\ University of Gießen, Germany
}

\begin{abstract}
The behavior of respondents in interview situations has been dealt on the one hand with respect to many empirical studies and on the other hand in connection with different theoretical approaches (Hyman 1954; Cannell \& Kahn 1968). In this paper the most relevant theoretical explanations are discussed and systematized from the point of view of the theory of reasoned action (Ajzen \& Fishbein 1980). Whereas this theory program has been used in many substantive fields, it has rarely been applied to the problem of interviewer effects and response sets. In this approach one assumes that the actors in interview situations decide according to cost-benefit calculations. The theory of reasoned action is viewed as an operationalized theory, discussed in more detail and formalized via structural equation models.

These models are empirically tested with the data of a survey specifically designed to perform such a method study. The reported contact rates of German with foreigners is the dependent variable under study. First, a model without interviewer variables is tested to explain respondent behavior in terms of norms, attitudes and some other determinants. Then the status and the age of interviewers are introduced as situational determinants of the respondents' behavior. For subgroup analyses the respondents are divided into three groups varying in the amount of the need for social approval. The models are tested according to two subgroups (low and high need for social approval) with the technique of multiple group comparison in LISREL (Jöreskog/Sörbom 1988). All models and results are interpreted in terms of the theory of reasoned action. At the end some conclusions for modelling interviewer effects and respondent behavior are discussed.
\end{abstract}

Key words: Theory of reasoned action, interviewer effects, respondent behavior, need for social approval, structural equation models, multiple group comparison.

\section{Introduction}

During the past few years, great changes have taken place in the analysis of social science data, especially concerning the subject of attitude variables. This has been accomplished by the consideration of measurement errors and by the use of multiple indicators and structural equation models. Based on the fundamental research of Blalock (1969) and Costner (1969) and their strict distinction between substantive theory and auxiliary theory, the prob-

\footnotetext{
* Part of the results have been presented by the first author at the International Conference on "Measurement Errors in Surveys" in Tucson, November 1990. We thank Gerda Lederer for her helpful comments.
} 
lem of nonrandom and random measurement errors has been formulated in a theoretical context instead as a problem of index construction. With the development of statistical tools (Structural Equation Models) the ideas of Blalock and Costner could be tested practically with empirical data. Furthermore empirical research on the effects of random measurement error and method effects as one source of nonrandom measurement error on parameter estimates are now known (Fuller 1987; Saris \& van Meures 1990; Biemer et al. 1991). But especially in the field of response sets and interviewer effects there has hardly been any progress. In most social science data analysis both of these sources of nonrandom measurement errors are ignored, even though the methodological literature keeps pointing out their relevance. A systematic comparison of research in the sense of a metaanalysis of the effect of reaction tendencies and of the influence of the interview on the estimation of parameters does not exist so far. However, one can assume that not only with respect to threatening questions but also in many other situation both types of nonrandom errors have considerable influence on the validity of the measurement or on the explained variance of the observed variables. There are many examples of descriptive research and several ad hoc models dealing with both issues (cf. Hyman 1954; Kahn/Cannell 1957; Cannell/Kahn 1968).

In this paper we intend to link four problems, allowing a theoretical explanation and an empirical test of the interviewer effect and the respondent's behavior:

1. Theory: By using a general theory of action we leave the level of descriptive research and simple ad hoc models (e.g. Cannell \& Kahn 1968) and use explicit theoretical explanations.

2. Method: By using structural equation models it is possible to split variances into explained variance via latent variables, random measurement errors, and nonrandom effects. In addition, the use of structural equation models here allows us to solve the problem of identification of the theoretical formulation with the help of theoretical variables, without recourse to measurements or to measured variables (MIMIC variables). ${ }^{1}$

3. Social desirability and interviewer effects: By simultaneously recording the tendency to respond in a desirable manner and the characteristics of the interviewer, it is possible, in this design, to test the combination of these effects. In nearly all other empirical research interviewer effects and the influence of social desirability are examined separately.

4. Design: By using an experimental design (deliberate sampling of interviewers according to sex and age), it is possible to vary the effects of the interviewer.

We actually consider all problems stated above. By using structural equation 
models (LISREL), random measurement errors can be controlled and nonrandom measurement errors (social desirability and interviewer effects) can be modelled explicitly. The situation sampling (cf. fourth point stated above) will be dealt with the analyses of subgroups according to situational parameters.

Let us finally discuss the second point (Method) in greater detail. Starting from Kish's pioneering work (Kish 1962) the amount of variance of the observed response due to interviewer variance has been computed and intraclass correlation coefficients used as a statistical measure (cf. also Groves \& Magilavy 1988). In the case of structural equation modeling one has to look at the parameters of the measurement model and the structural model on one hand and at the observed means and the means of the latent variables on the other. In the usual procedures to estimate reliability and validity in multiple indicator models via confirmatory factor analysis the following model is assumed (cf. Bynner 1990, Bollen 1989):

$$
\mathrm{X}=\lambda \xi+\delta
$$

where

- $\mathrm{X}=$ Vector of observed indicators

- $\xi=$ Vector of latent variables (traits)

- $\lambda=$ Matrix of factor loadings

- $\delta=$ Vector of measurement errors

Saris and Andrews (1991) have discussed some of the drawbacks in the application of this model in their paper. By using a Multitrait-MultimethodMultitime design (MTMMMT) and using a true score model they can disentangle specific, unique and methods effects for the single items. However they do not deal with nonrandom errors like response sets or interviewer effects (Saris \& Andrews 1991: 580), which is our main topic. The variance decomposition approach just described can now be generalized to take into account social desirability and interviewer characteristics as additional determinants of the responses of the interviewees (X). Figure 1 contains a path diagram of the relationships just mentioned.

In practice of most social research it is usually implicitly assumed that the chosen methods, uniqueness, response sets and attributes of interviewers have no effects. Examples of measurement models taking into account at least social desirability and random measurement error can be found only in Carmines and Zeller (1980: 102-169). The discussion of the effects of response sets has concentrated on how response sets and interviewer effects may influence the means of observed variables and factor loadings. In our model theoretical reasoning has led us to specify that certain interviewer 


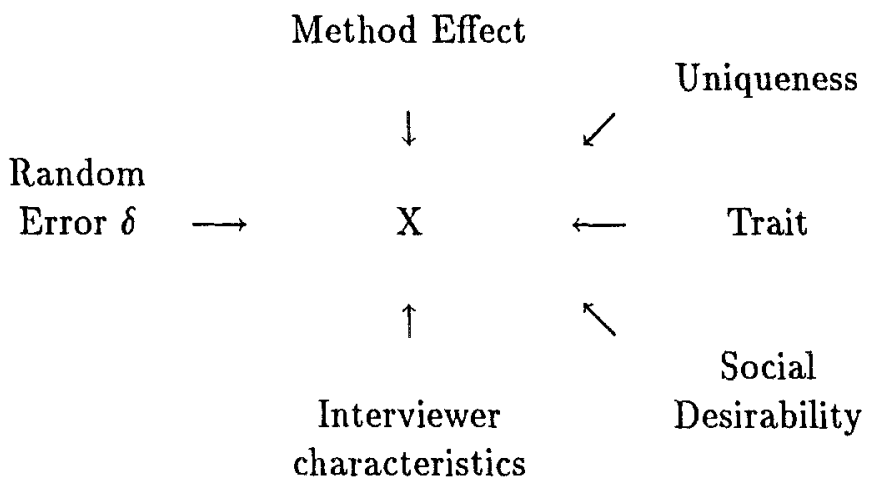

Fig. 1. Variance decomposition of items.

attributes (age and status) should only influence the structural part of the model contrary to Figure 1 (cf. Section 2). But the interviewer attributes are modified by the effect of social desirability of the respondents. Therefore we have decided to use the multiple-group option of LISREL to test whether the interviewer effects are the same for the high and the low social desirability group (cf. Section 4.3). Because of the small sample size we have not computed the structured means (means of latent variables) as additional parameters. This paper should therefore help to solve the practical question of considering interviewer effects. We do not restrict ourselves to a purely theoretical analysis with descriptive results valid for a specific area. On the contrary, we want to show how theory-orientated measurement instruments are used to evaluate reactive tendencies and interviewer effects. In addition, we demonstrate how the effect of these variables can be controlled by suitable statistical analysis in order to avoid specification errors due to leaving out variables in the estimation of parameters.

\section{Structural equation model for the theory of reasoned action}

In the following section we discuss the theory of reasoned action as a framework for explaining interviewer effects and social desirability. According to this theory neither demographic variables nor general attitudes of the interviewer which are used in most of the research on interviewer effects have any direct effect on the behavior of the respondents.

According to Ajzen and Fishbein the existence of behavior is based on four different elements (Ajzen \& Fishbein 1977: 889; Ajzen \& Fishbein 1980: 39): 
1. the action

2. the target at which the behavior is directed

3. the context in which the behavior occurs

4. the time at which the behavior is performed

Each element can be either specific for a certain behavior or it can be more common. Therefore, a specific behavior can be goal directed but it can appear in different contexts and at different times. Attitude and behavior only correspond if there is a relationship between attitude and the four other elements of behavior. Ajzen and Fishbein state as an example that an attitude - e.g. towards church (i.e. somebody speaks of "my church") is related to a certain criterion of behavior, based on various observations of behavior (visiting a church, behavior in donation) which can be found in various contexts and at different times (Ajzen \& Fishbein 1977: 890). Criteria of behavior can be split up in single-act criteria and multiple-act criteria (Ajzen \& Fishbein 1977: 891). A single-act criteria means the appearance or non-appearance of a single act of behavior, observed on a single occasion. Multiple-act criteria are related to the appearance or non-appearance of several acts of behavior, observed on a single occasion. ${ }^{2}$

How can the relationship between attitude and behavior be interpreted in an empirical theory in order to explain the processes from attitude formation to overt behavior, i.e., with all "intervening" variables? The biggest part of behavior of interest to a research worker is assumed to be under volitional control and that a person, in a given situation, has or creates a specific intention which influences behavior (Ajzen \& Fishbein 1978: 406).

$$
B \sim B I=(A t t) w_{0}+(N o r m) w_{1}^{3}
$$

"B" is the overt behavior, "BI" the behavioral intention, "Att" the attitude toward the behavior, "Norm" the subjective norm and $w_{0} / w_{1}$ are empirical weights which indicate the intensity of influence of attitude or norm. ${ }^{4}$ The variable "Att" and the variable "Norm" are built analytically as expectancy value products (cf. Ajzen \& Fishbein 1978: 407):

$$
A t t=\sum_{i=1}^{n} B_{i} a_{i} ; \quad \text { Norm }=\sum_{j=1}^{m} N B_{j} M c_{j}^{5}
$$

$B_{i}$ is the assumed probability (expectancies) that an act of manifested behavior leads to result $i$ (beliefs that the behavior leads to certain outcomes), $a_{i}$ is the evaluation of the outcomes and $n$ is the number of cognitions. $N B_{j}$ is the assumed probability that members of a reference 
group expect the performance of the expected behavior (beliefs that specific referents think one should or should not perform the behavior), $M c_{j}$ is the motivation for conformity with the perceived expectancies of the reference group (motivation to comply with specific referents) and $m$ is the number of reference groups (cf. Ajzen \& Fishbein 1980: 8ff) ${ }^{6}$ If attitude (Att) does not refer to just one cognition and subjective norm (Norm) does not relate to just one reference group the theory is formalized as follows (Ajzen \& Fishbein 1978: 408):

$$
B \sim B I=\left(\sum_{i=1}^{n} B_{i} a_{i}\right) w_{0}+\left(\sum_{j=1}^{m} N B_{j} M c_{j}\right) w_{1}
$$

Fishbein has explained in his earlier analyses that the component of expectancies $N B_{j}$ must be divided into two types (Fishbein 1967: 489):

Type 1 Individual ideas of what a person feels, what he/she should do, i.e., the idea of a norm or rule of behavior.

Type 2 Individual ideas of what a person feels, of what he/she should do according to society, i.e. the idea of a norm or ruie of behavior according to significant others. ${ }^{7}$

We want to add one more type to the type formation according to Fishbein (1967). This new type can be seen as a kind of connective theory which deals with the influence of the situation "interview" on the action person:

Type 3 Individual ideas of what a a person feels, what he/she should do according to the opinion on or interpretation of the situation, i.e., the idea of a norm or a rule of behavior according to situational points of view (which also includes the interviewer).

It is easy to integrate this addition in the Ajzen and Fishbein model since we only make a distinction according to special reference groups and since we stick to the determinants of behavior and the expectancy-value constructs (i.e. the theory is not changed). This distinction according to specific reference groups includes the additional hypothesis that for the formation of subjective norm the reference group can have different degrees of importance. These lead to the following changes of the formula stated above:

$$
\begin{aligned}
B \sim B I= & \left(\sum_{i=1}^{n} B_{i} a_{i}\right) w_{0}+\left[\left(\sum_{j=1}^{m} N B_{j} M c_{j}\right) w_{1}+\left(\sum_{k=1}^{o} N B_{k} M c_{k}\right) w_{2}\right. \\
& \left.+\left(\sum_{l=1}^{p} N B_{l} M c_{l}\right) w_{3}\right]
\end{aligned}
$$




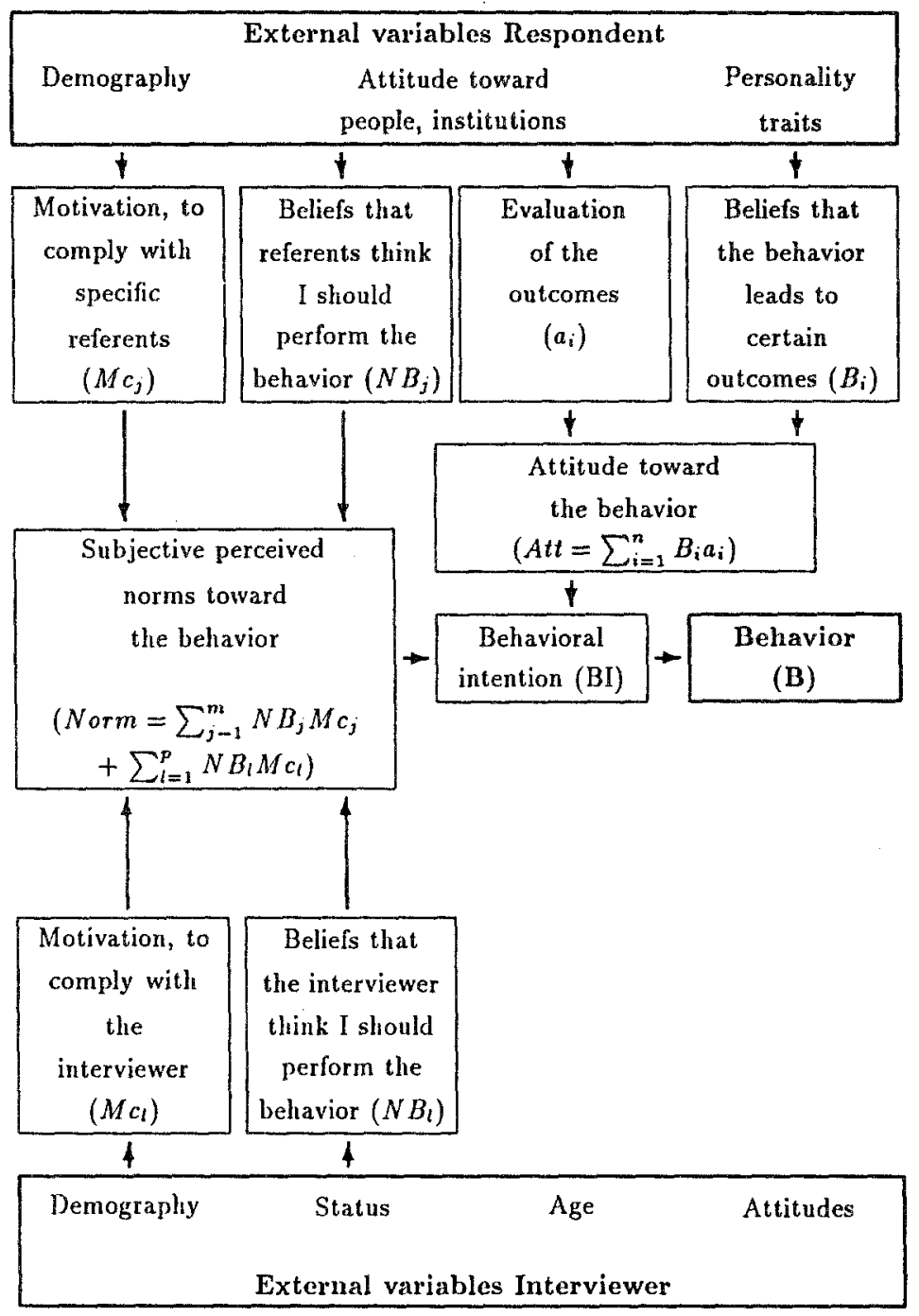

The expectation-value formula of type 1 has been dropped because of the clearness of the scheme.

Fig. 2. Extended model of the theory of reasoned action and interviewer variables.

The summation $j \ldots m$ relates to type 1 (I), the summation $k \ldots o$ relates to type 2 (e.g. parents, colleagues, friends) and the summation $l \ldots p$ relates to type 3 (Interviewer). ${ }^{8}$ The model of Ajzen and Fishbein (1980: 84) can now be enlarged by using interviewer variables which have, according to us, an additional influence on the subjective norm of the respondents (cf. Figure 2). 


\subsection{Formulation of a substantive model with a method theory}

In the following, the constructs of the theoretical approach we chose are applied to a causal model. This model will explain contact behavior toward foreign workers as the result of different attitudes on one hand and as the result of different subjective norms on the other. This describes the main features of the substantive theory (concerning sample survey and measurement instruments, cf. Section 3).

As to the possibility of modelling the approach of Ajzen and Fishbein, the shaping of the "normative" constructs can depend on the respondent's situation and the biases connected with it. In other words: The characteristics of the interview (including the behavior and the status of the interviewer) and the biases of the respondent can influence the normative motivation or attitude of expectation, leading to other predictions of intended and (actual) behavior. This does, in the main, describe the position of method theory.

A model which postulates substantive theoretical connections as well as the influences of the interviewer on the respondent's behavior must, therefore, be formulated in such a way that it also identifies possible biases in the normative construct in addition to the substantial connections. Since there must be simultaneous analyses of methods for the identification of systematic influences of interviewer and respondent with the simultaneous control of random measurement errors, the substantial models are formulated as structural equation models. In the empirical analyses they are calculated with the program LISREL (cf. Jöreskog \& Sörbom 1988).

In order to be able to examine the model for a specific problem (in this case, the behavior toward foreign workers), the components of the AjzenFishbein model must be transferred into theoretical constructs with the respective indicators. This transformation can lead to difficulties if the measurement instruments (questions etc.) were not exclusively conceived for the theoretical approach we sketched here. For this reason, we can only take into account those components of the model for which operationalizations are provided in the research.

A restricted Ajzen-Fishbein model serves as a basis for the development of a substantial structural equation model. On the basis of this model the following relations between constructs of the Ajzen-Fishbein model and substantial constructs (cf. Figure 3) obtains:

- The private contact with foreigners (CONTACT) in various situations (place of work, place of living etc.) represent the construct behavior. The indicator of CONTACT is the index Contact1 which summarizes the questions of private contacts with foreigners in various situations. 


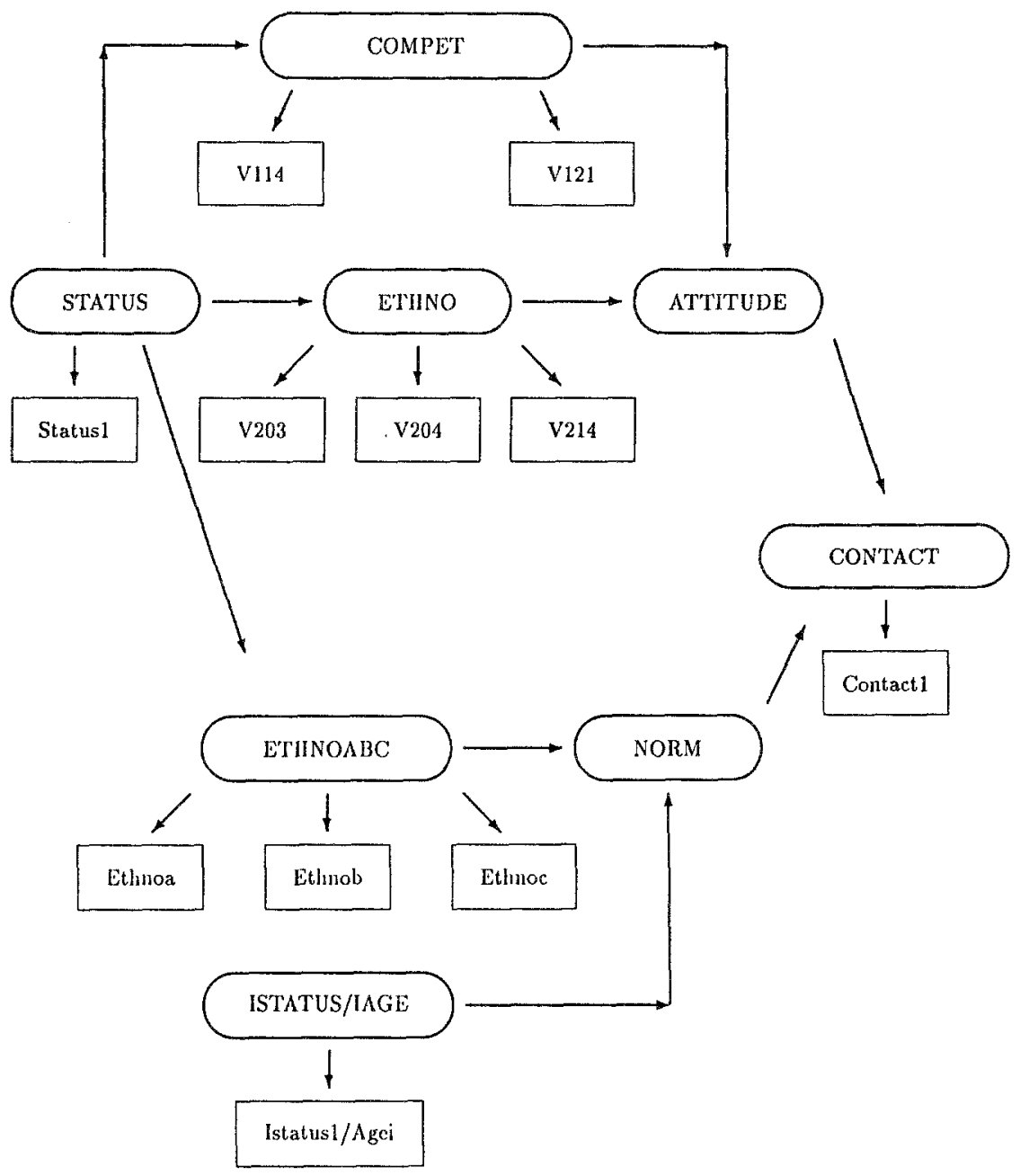

Indicators (manifest variables)

$\bigcirc$ CONSTRUCTS (latent variables)

Fig. 3. Operationalization of the theory of reasoned action and interviewer variables.

- The perceived situation of competition with foreigners (COMPET) and the ethocentristic attitude toward foreigners (ETHNO) represent external variables in the sense of Ajzen and Fishbein. The indicators of the perceived situation of competition are related to the attitude items toward the place of work (V114) and toward living space (V121), the indicators of ethnocentrism are related to the attitude items toward confidence in foreig- 
ners (V203), distance to foreigners (V204) and living with foreigners (V214).

- The perceived hostility against foreigners in the primary milieu (ETHNOABC) shall also represent an external variable in the sense of Ajzen and Fishbein. The indicators of ETHNOABC are the additive indices Ethnoa, Ethnob and Ethnoc which were composed of four statements of ethnocentristic attitudes for the three best relatives/friends/acquaintances.

- The respondent's status referring to eduction and profession (STATUS) shall represent another external variable. The indicator of STATUS is an index Status1 which combines the values of education and profession of the respondent.

- The interviewer's status referring to education and profession (ISTATUS) and his age (IAGE) represents the constructs of the extended AjzenFishbein model. The indicator of ISTATUS is an index Istatus1 which combines the values of education and profession of the interviewer. The indicator of IAGE are the age groups of the interviewer (Agei).

The reduced model of the theory of reasoned action includes two more constructs which, however, cannot be operationalized with the available measurement instruments (cf. Figure 3). This concerns the attitude toward certain behavior (ATTITUDE) and the subjective norm (NORM). They will be treated as MIMIC variables in the structural equation model we want to examine. This kind of modelling is a special case of the introduction of so called phantom variables with whose help one can generally test constructs of any kind as long as the problem of identification is solved (see Rindskopf 1984). The formulation refers to the generalized form of a structural equation model (cf. Graff \& Schmidt 1982) and allows the test of theoretical models at least indirectly where there are no direct measurements of the constructs.

The substantial model (nuclear theory) can be stated more precisely as follows: external variables like, e.g., STATUS explain various beliefs concerning social norms and specific attitudes. Persons with high status are more likely to be found in milieus friendly to foreigners, whereas persons with low status are likely to be found in primary environments hostile to foreigners. This is directly related to the attitude toward foreigners as rivals at work or in the living space. The more primary environments document hostility to foreigners, the more likely it is that the foreigners are regarded as competitors. Increasing feelings of competition and increasing expression of prejudice reduce the establishment of private contacts to foreigners (cf. Krauth/Porst 1984). The hypotheses about relationships between the latent variables of the substantive theory are graphically depicted in Figure 3.

The theoretical extension of the method can be detailed as follows: The 
subjective norm (NORM) is influenced by the situational influences during the process of interviewing. The respondent, therefore, orients his response not only according to these attitudes and his individually adapted norms, but also according to the characteristics of the interviewer. These characteristics can be more or less visible (e.g. age, status) and they can also concern the interviewer's attitude. The addition to the substantive theoretical model, therefore, is to find out in what way the respondent's norms are influenced by situational characteristics of the interview situation. The interviewer characteristics status (ISTATUS) and age (IAGE) are added as additional predictors of NORM. Since the interviewer characteristics are not independent constructs, the influence of the interviewer's characteristics are examined individually and not simultaneously.

The relationships between the interviewer variables and the latent variables of the substantive theory are of two types: the influence of the interviewer on the behavior construct (CONTACT) is postulated via the value * expectancy variable NORM (indirect influence), while the influence of the interviewer on the attitude constructs ETHNO and COMPET is postulated directly. The hypotheses about relationships between the latent variables of the substantive theory and the interviewer variables can be stated as follows:

- The interviewer's status (ISTATUS) has a negative influence on the subjective norm (NORM), i.e., the higher the interviewer's status, the less relevant become the norms hostile to foreigners in the interview situation.

- The interviewer's status (ISTATUS) is negatively related to the ethnocentric attitudes of the respondent (ETHNO) and the feeling of competition toward foreigners (COMPET).

- The interviewer's age (IAGE) has a positive influence on the subjective norm (NORM), i.e., the older the interviewer, the more relevant become the norms hostile to foreigners in the interview situation.

- The interviewer's age (IAGE) is positively related to the ethnocentric attitudes of the respondent (ETHNO) and the feeling of competition toward foreigners (COMPET).

All hypotheses are formulated according to the structural equations of the model. Hypotheses about different parameters of the measurement model are not postulated.

The interviewer is regarded as a member of a further reference group in the sense of the argument stated above (cf. Figure 3). One must assume that the respondent expects an interviewer with higher status, for example, to be friendly toward foreigners. 


\subsection{Operationalization of the respondent behavior according to social desirability and the formation of subgroups}

For the operationalization of the respondent behavior according to social desirability we used the short version of the Marlowe-Crowne SD-Scale of Schuessler (1982) consisting of 10 items. This scale is meant to show respondent behavior according to social desirability in the form of a need for social approval (cf. Crowne \& Marlowe 1960). First of all, we developed an additive index of 10 items (in the following called MCSD-Scale). This index is onedimensional, according to the factor analysis (Varimax rotation, criteria of eigenvalue $>1$ ). The MCSD-Scale ranges from 18 to 36 , with half of respondents obtaining values between 27 and 30 .

The scale is mainly used in order to form groups of the respondents according to their tendency to respond in a socially desirable manner and to discover conditions for the actualization of situational effects of bias. Social desirability is not defined as a construct and is not additionally integrated in the nuclear model (cf. Reinecke 1985, Hermann \& Streng 1986). Instead, it functions as a parameter of the situational conditions.

The respondents were grouped to form quartiles according to their relative susceptibility to social desirability. The first group was composed of respondents with low social desirability scores; the second group, made up of two quartiles, was composed of respondents with middle social desirability scores; and the third group consisted of respondents with high scores.

According to the analysis of Reinecke (1991a) respondents of the first quartile (SD-1) and of the fourth quartile (SD-4) express tendencies for social desirability related to their specific norms. The actualization of different norms in the interview situation can be explained with the respondent's age (Reinecke 1991a: 314): If younger respondents see their need for approval in the socially undesirable categories of the scale, then the socially undesirable categories are, for them, the categories of high social desirability. A distinction has to be made in the designation of attitudes commonly perceived as being moral and attitudes perceived as socially desirable - which is in some cases the same and in some, it seems, the opposite. Also the interviewer's influence plays an important role: If the respondent anticipates that the interviewer is hostile to foreigners, not only the specific norm of social desirability of the respondent, but also the interviewer's attitude is decisive for the respondent behavior.

For the respondents of the fourth quartile (SD-4) - mostly older respondents - an attitude hostile to foreigners is more likely to be desirable. Anticipation toward the interviewer has the effect that an interviewer's hostile attitude to foreigners explains a part of the variance of the respondent's 
ethnocentrism. For the respondents of the first quartile (SD-1) - mostly younger respondents - an attitude hostile to foreigners is most likely socially undesirable. Here, also, anticipation toward the interviewer has an effect, but in the reverse direction: an interviewer's positive attitude to foreigners explains a great part of the variance of the respondent's ethnocentrism (Reinecke 1991a: 315).

Based on these results we will now use the subgroups of the first and fourth quartiles of the MCSD-Scale (SD-1, SD-4) to examine the substantial models, including interviewer variables (subgroup models). According to the method theory the following hypotheses are stated for the subgroups:

- First subgroup (desirability is defined as to friendliness toward foreigners).

- The higher the interviewer's status, the less likely will the respondent's subjective norm be to hostile behavior to foreigners. This relation will be well developed if the need for social recognition is shown via friendly behavior to foreigners. An interviewer with higher status will strengthen the friendliness to foreigners.

- The older the interviewer is, the more likely will the subjective norm of the respondent be hostile behavior to foreigners. This relation will be weakly developed if the need for social approval is shown via friendly behavior to foreigners. The age of the interviewer will have little influence on the friendliness toward foreigners.

- Second subgroup (desirability is defined as hostility toward foreigners)

- The higher the interviewer's status, the less likely will be the respondent's subjective norm be to hostile behavior to foreigners. This relation will be weakly developed if the need for social approval is shown via hostile behavior to foreigners. Even if the interviewer has a higher status the hostility to foreigners remains.

- The older the interviewer, the more likely will the subjective norm of the respondent be to hostile behavior to foreigners. This relation will be well developed if the need for social approval is shown via hostile behavior to foreigners. An older interviewer will strengthen the hostility to foreigners.

In all subgroup analyses the assumption is made that the measurement theory, i.e. the factor loadings, are invariant over the groups. This means that those coefficients in multiple-group comparisons are set equal. 


\section{Sample, measurement instruments, and descriptive results}

\subsection{Sample}

The analysis of bias in the interview situation demands a selection of interviewers diverse in the variables whose effects are to be examined. The interviewers are chosen from different age- and status groups.

According to the characteristics, the interviewers equally divided among male and female person, $60 \%$ are younger ( $\leq 30$ years old) and $40 \%$ are older persons ( $\geq 40$ years old). In addition, $60 \%$ are inexperienced and $40 \%$ are experienced interviewers. Education and status, are somewhat higher than comparable teams of interviewers. The older interviewers are more likely to have a lower degree of education and, therefore, a lower status, the younger interviewers are more likely to have a higher degree of education due to the recruitment of students.

With the help of the resident's registration office in Essen a random sample was selected in two districts of the city. ${ }^{9}$ The prospective respondents were informed in a letter about the forthcoming survey and the visit of an interviewer. The interviewers received the adresses of persons previously notified by mail. The assignment of adresses to specific interviewers was random though for practical reasons no interviewer worked in two different districts.

The survey was carried out in Spring 1986. 125 interviews were conducted, 51 of them in the district Essen-Holsterhausen and 74 in the district EssenAltenessen-Nord.

In order to determine the demographic variables of the interviewers and their attitudes, the interviewers had to complete a questionnaire. Data of the interviewers could be related to the data of the respondents. This made it possible to differentiate certain groups of respondents according to their situation characteristics and to determine possible relations between methodical constructs and substantial constructs.

\subsection{Measurement instruments}

For the methods research conducted here, a substantial questionnaire was developed. It was registered as "Conditions for the Integration of Foreign Employees in the Ruhr Area" and was approved by the German Science Foundation (DFG) as accompanying research of the research project "Cultural and Ethnic Identity of Work Migrants in an Intercontextual and Intergenerational Comparison" (cf. Esser et al. 1986). The measuring instruments are described as follows: For the construct STATUS, the Index Status1 was developed with the help of questions about education and profession. 
The items concerning the feeling of competition and the situation of life are taken from the study "Social-economic Conditions for the Integration of Foreign Workers of the Ruhr Area" (Esser et al. 1983) in order to become familiar with the respondents' assumption concerning the current life situation, expected developments on the labour market and the perception of foreigners as competitors. Items V114 and V121 were selected for the construct COMPET.

The items concerning ethnocentrism are taken from various studies (e.g. Esser et al. 1983) and scales (cf. ZUMA-Schalehandbook 1983). 10 items are positively formulated so that a person high in ethnocentrism would have to approve them, 6 are negatively formulated so that an ethnocentric person would disagree with them. The variables V203, V204 and V214 were selected for the construct ETHNO.

The questions concerning the primary milieu correspond, with regard to the survey design, to the question of the ego-centered network within the General German Social Survey (ALLBUS) of 1980. Of the three best friends/relatives/acquaintances outside one's own household, demographic variables (sex, age, education), subjective estimates of the ethnocentrism of friends/relatives/acquaintances, the contact rate with these three persons and the connectivity of this network were ascertained. The indices Ethnoa, Ethnob and Ethnoc are formed of the subjective estimates for the construct ETHNOABC.

The questions concerning the interethnic contacts are subdivided into two complexes: contacts at the places of work or study and contacts in the primary or secondary milieu. The index Contact 1 is constructed of both complexes for the construct CONTACT.

The items concerning social desirability are taken from a translated short version of the Marlowe-Crowne-SD-Scale (cf. Section 2.2).

\section{Results}

In the following we compare the results of the operationalized models (cf. Figure 2) for the whole population without interviewer variables, then with the interviewer variables and, finally, for the subgroups (cf. Scheme in Figure 4). The computation of single models is made with the program LISREL (cf. Jöreskog \& Sörbom 1988) where only covariance matrices are used as input matrices. For the models concerning the whole population we refer to standardized coefficients and for the analysis of subgroups we list unstandardized coefficients. Concerning the examination of the hypotheses, most weight is put on the structural coefficients, the residual variances and the covari- 


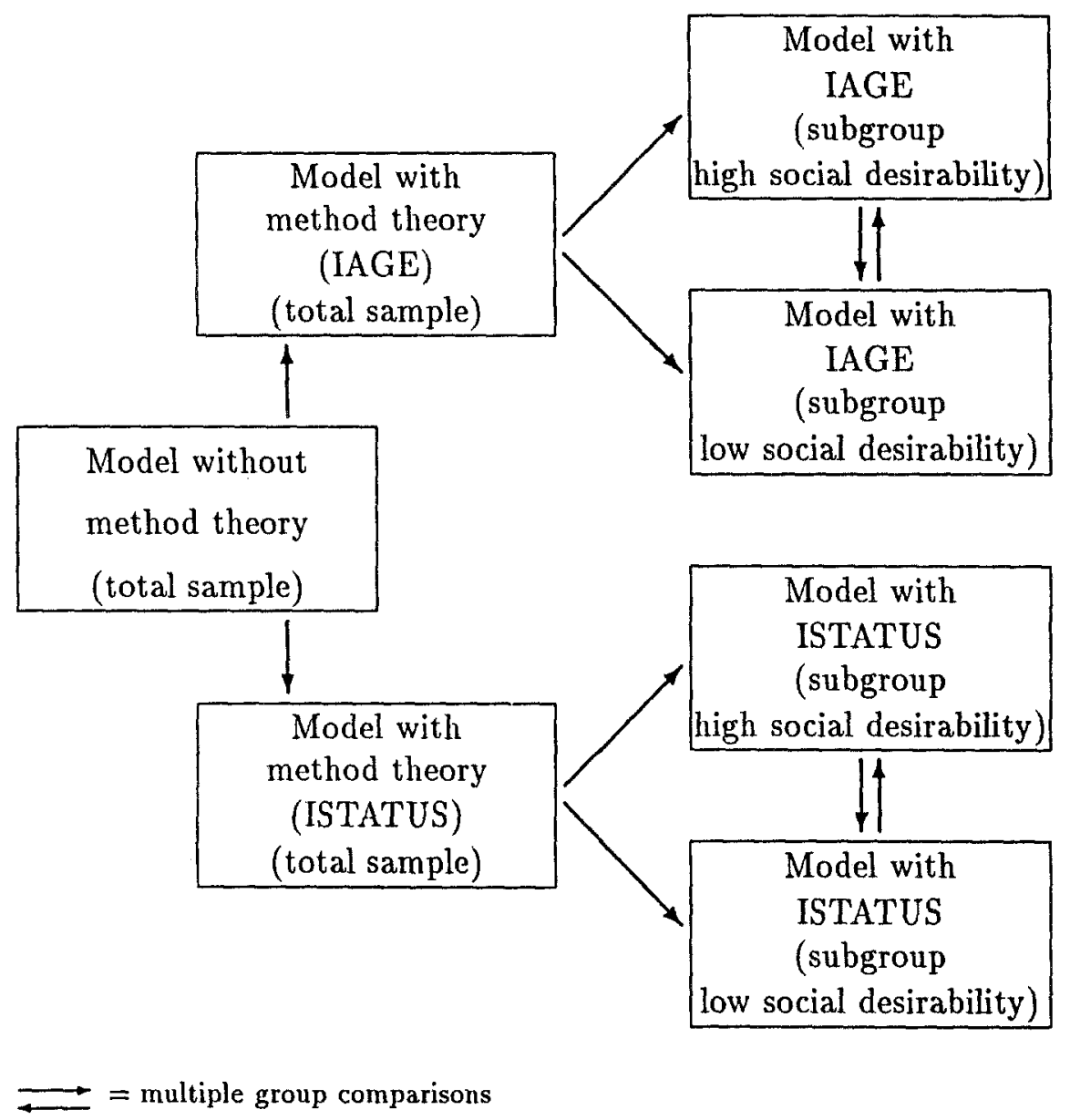

Fig. 4. Sequence of model testing.

ances. The presentation of factor loadings has been dropped for reasons of space. In all models the factor loadings have reasonable sizes $(>0.60$, cf. Reinecke 1991b).

\subsection{Model of the total sample}

The relations on the constructs of the substantive theory are largely corroborated: STATUS has a negative effect on ETHNOABC $(-0.434)$ and COMPET $(-0.190)$, ETHNO and COMPET have positive effects on ATTITUDE (0.874 and 0.177). ATTITUDE and NORM have negative effects on CONTACT $(-0.277$ and -0.203 respectively). The postulated direct effect from STATUS to ETHNO does not exist. The necessity to specify different exter- 
nal variables in the sense of Ajzen and Fishbein becomes clear regarding the different sizes of path coefficients from COMPET to ATTITUDE and from ETHNO to ATTITUDE. The respondent's hostility to foreigners has a stronger meaning for ATTITUDE than his feeling of competition. This means that the intention to have private contact to foreigners can be explained much more by personal affection or dislike than by situational factors such as life space and workplace which are rather controlled politically. The fit of the model is acceptable $\left(\chi^{2}=23.80\right.$ with 28 degrees of freedom, $\mathrm{GFI}=$ $0.963)$. There are no greater deviations between empirical and estimated covariances. There are also no hints of model improvements in the Modification Indices. Therefore, the model of the substantive theory can be accepted for further analyses.

\subsection{Models of the total sample with interviewer variables included}

In the following the results of two models are combined: the model with the construct interviewer status (ISTATUS) and the model with the interviewer age (IAGE).

According to the results of the theoretical relationships of both models there are hardly any differences to those of the model without interviewer variables: STATUS has negative effects on ETHNOABC and COMPET $(-0.434$ or -0.185$)$, ETHNO and COMPET have positive effects on ATTITUDE (0.743 or 0.342$)$. ATTITUDE and NORM have negative effects on CONTACT $(-0.293$ or -0.273$)$.

However, the status of the interviewer becomes an important predictor for the subjective norm: the higher this is, the less norms hostile to foreigners become relevant for private contacts. The hypothesis about the influence of the interviewer's age has been corroborated only slightly. On the other hand, there are significant residual correlations between ISTATUS and COMPET $(0.150)$ and between IAGE and ETHNO (0.301). ${ }^{10}$ These results must be regarded in relation to the effects of ISTATUS on NORM, or IAGE on NORM. Concerning the latter, the effects correspond in their direction with the postulated hypothesis, but they are not significant. On the other hand, it becomes clear that the interviewer variables have an influence on the attitude variables ETHNO and COMPET: a feeling of competition is oriented to the interviewer's status; hostility to foreigners is oriented to the interviewer's age. The latter relationship is the stronger and is also confirmed by other empirical studies. This means that interviewer characteristics play a role in determining an attitude but not so much that the interviewer is regarded as a further reference individual in the sense of the variable norm 
in the Ajzen-Fishbein model. The following analysis will show to what extent this is also true for the subgroups.

The fit of the models are acceptable $\left(\chi^{2}=32.93\right.$ with 36 degrees of freedom for the model with ISTATUS and $\chi^{2}=37.79$ with 36 degrees of freedom for the model with IAGE). There are no greater deviations between empirical and estimated covariances. Therefore, the models of the substantive theory with interviewer variables included, can be accepted for the subgroup analyses.

\subsection{Subgroup analysis according to social desirability}

\subsubsection{Model with interviewer status}

In the following we show the computation of the structural equation model according to the division into groups made in Section 2.2 (low desirability versus high desirability). The computations are again made with the program LISREL, where, however, the connections between the indicators (covariance matrix) are regarded as seperated into different groups (concerning the technique of multiple-group comparison, cf. Jöreskog \& Sörbom 1988; Sörbom 1979; 1982). The input information separated into groups ${ }^{11}$ is computed simultaneously. The advantage of this is that the covariances between variables can be tested explicitly according to certain criteria. Here the criterium is the tendency to social desirability, which is low according to the values of the MCSD-Scale in the one group and high according to the values of the MCSD-Scale in the other.

The starting point of the multiple-group comparison is a so-called "base line model" (cf. Sobel \& Bohrnstedt 1985: 161ff). The base line model used here assumes equal modeling of the measurement theory, the substantive theory, and the method theory (i.e. the influence of the interviewer characteristics, cf. model variant 1, Table 1). All parameter matrices (except of the error variances) are invariant beyond two groups, i.e. for them equal coefficients (except for the error variances) are estimated. This model implies that there are no differences in effects between the substantial constructs or between the method and the substantial constructs. In the case this model is not acceptable, the differentiation of the respondents according to their tendency to respond in a socially desirable manner would have no influence on connections in the substantive theory and it would have no influence on the effect of interviewer variables. Because the structural coefficents are gradually set free ${ }^{12}$ it can be tested if this leads to significant $\chi^{2}$-improvements.

The model variants 2 to 6 (so-called "nested models", cf. Sobel \& Bohrnstedt 1985) in Table 1 clarify this process and the results belonging to 
Table 1. Sequence of model testing in the multiple group comparisons (model with ISTATUS)

\begin{tabular}{|c|c|c|c|c|}
\hline & \multicolumn{2}{|c|}{ Total fit } & \multicolumn{2}{|c|}{ Fit of the subgroups } \\
\hline Type of models & $\chi^{2}$ & $\mathrm{df}$ & $G F I_{1}$ & $G F T_{2}$ \\
\hline 1: $\mathrm{LY}=\overline{\mathrm{IN}} \mathrm{BE}=\mathrm{IN} \mathrm{GA}=\mathrm{IN}$ & 151.83 & 84 & .720 & .755 \\
\hline $\begin{array}{l}2: \mathrm{LY}=\mathrm{IN} \mathrm{BE}=\mathrm{PS} \text { GA=IN } \\
\text { NEQ: ISTATUS - NORM }\end{array}$ & 151.18 & 83 & .721 & .753 \\
\hline $\begin{array}{l}\text { 3: LY=IN BE }=I N \text { GA }=\text { PS } \\
\text { NEQ: STATUS - ETINOABC }\end{array}$ & 146.12 & 83 & .721 & 766 \\
\hline $\begin{array}{l}\text { 4: } L Y=I N \text { BE }=I N G A=P S \\
\text { NEQ: STATUS - ETHNOABC } \\
\text { RES: V214 - Ethnoa }\end{array}$ & 123.97 & 81 & 746 & .792 \\
\hline $\begin{array}{l}\text { 5: LY }=I N \text { BE }=I N \text { GA }=\text { PS } \\
\text { NEQ: STATUS - ETIINOABC } \\
\text { RES: V214 - EUHoa } \\
\text { RES: V114 - V203 } \\
\text { RES: V214 - V203 }\end{array}$ & 102.03 & 77 & .792 & .811 \\
\hline $\begin{array}{l}\text { 6: } L Y=I N \text { BE }=I N \text { GA=PS } \\
\text { NEQ: STATUS - ETINOA BC } \\
\text { RES: V214 - Ethnoa } \\
\text { RES: V114 - V203 } \\
\text { RES: V214 - V203 } \\
\text { RES: ISTATUS - COMPET }\end{array}$ & 95.54 & 75 & 803 & 814 \\
\hline
\end{tabular}

PS $=$ Matrices BEta, GAmma and Lambda $Y$ have the same causal structure but different coefficients across groups.

IN = Matrices BEta, GAmma and Lambda $Y$ have the same causal structure and identical coefficients across groups.

$\mathrm{NEQ}=$ Not EQual means that the numerical relation between two constructs may differ across groups.

RES $=$ RESidual Covariances between constructs or between measured variables may differ across groups.

it. ${ }^{13}$ The comparison of model variants is made as follows: the "base line model" (variant 1) is the starting point for the computation of $\chi^{2}$-differences. If a significant $\chi^{2}$-improvement is gained (Q-Ratio $\left.>2\right)$ by giving up restrictions (further variant of the model), the "new" model is accepted. ${ }^{14}$

According to the results there is no significant $\chi^{2}$-improvement (QRatio $>2$ ) from model variant 1 to model variant 2 . This means that no difference in the influence of the interviewer status can be found because of the differentiation concerning the tendency of social desirability. However, there are improvements from model variant 1 to model variant 3 and from model variant 3 to model variants 4,5 and 6 .

First, the variation in the relationship between STATUS und ETHNOABC leads to a small significant $\chi^{2}$-improvement (variant 3 ). Second, the specification of residual covariances between certain measured variables leads to highly significant $\chi^{2}$-improvements (variants 4 and 5). Third, the specification of a residual covariance between ISTATUS and COMPET leads to a further significant $\chi^{2}$-improvement which indicates a different influence of interviewer variables over the groups (variant 6).

The fit indices of the accepted model variant 6 have similar values $\left(G F I_{1}=\right.$ 
0.803 and $G F I_{2}=0.814$ ). These values are low because of the high model restriction.

For both groups there are no greater deviations (values in the matrix Normalized Residuals $\geq 2.0$ ) between empirical and estimated covariances.

Interpretations of the results of the accepted model variant 6 will focus on the relation between ISTATUS and constructs of the substantive theory and their differences over the groups.

The results in Table 2 show that there is a weak, non-significant influence of interviewer status on subjective norm in both groups $(-0.185)$. This means also that there is no influence from ISTATUS via NORM on the behavior construct CONTACT. But the results show certain influences from ISTATUS on the attitude constructs ETHNO and COMPET (cf. Table 2). For the first group (low MCSD-score) there are significant negative residual covariances between ISTATUS and COMPET $(-0.323)$ and ISTATUS and ETHNO $(-0.323)$. This means that subjects with the tendency to behave in a socially desirable manner (here friendliness to foreigners) adjust their response behavior according to the status of the interviewer: the higher the status of the interviewer, the lower is both the competition and the ethnocentrism against foreigners. For the second group (high MCSD-score) there are positive residual covariances, significant between ISTATUS and COMPET $(0.850)$ and non-significant between ISTATUS and ETHNO (0.079). This means that persons with the tendency to behave in a socially desirable manner (here hostility to foreigners) adjust their response behavior in the opposite sense: the higher the status of the interviewer, the higher is both the competition and the ethnocentrism against foreigners.

Considering all the results reported in Table 2 it can be shown that the first group of respondents has a more complete attitude structure (high residual covariances) than the second group of respondents. In the latter, the attitude structure is more heterogeneous (low residual covariances).

\subsubsection{Model with interviewer age}

In the following we show the stepwise calculation of multiple-group comparisons of the model according to interviewer age (Table 3 ). The results show that there is no significant difference between model variant 1 and model variant 2. Thus a variation of the relation between IAGE and NORM does not lead to a significant model improvement as postulated. Again, the variation of the relationship between the constructs STATUS and ETHNOABC leads to a significant $\chi^{2}$-improvement (variant 3 ) and again, the specification of residual covariances between certain measured variables leads to highly significant $\chi^{2}$-improvements (variant 5 and 6). In contrast to the model with interviewer status the specification of a residual covariance 
Table 2. Variant 6 (structural coefficients)

\begin{tabular}{|c|c|c|c|}
\hline \multirow[t]{2}{*}{ Beta } & \multicolumn{3}{|c|}{ Subgroup low MCSD-score (SD-1) } \\
\hline & STATUS & ETINOABC & ETHNO \\
\hline ETHNOABC & $-.436(-4.332)$ & \multirow[b]{5}{*}{1.000} & \multirow{5}{*}{1.000} \\
\hline ETHNO & $-.003(-.066)$ & & \\
\hline COMPET & $-.104(-1.885)$ & & \\
\hline ATTITUDE & & & \\
\hline \multirow{2}{*}{ NORM } & & & \\
\hline & ISTATUS & & \\
\hline \multirow[t]{2}{*}{ NORM } & $-.079(-.750)$ & & \\
\hline & COMPET & ATTITUDE & NORM \\
\hline \multirow{2}{*}{$\begin{array}{l}\text { ATTITUDE } \\
\text { CONTACT } \\
\end{array}$} & $-.541(-1.604)$ & \multirow[b]{2}{*}{$.393(1.337)$} & \multirow[b]{2}{*}{$-.403(-2.723)$} \\
\hline & & & \\
\hline \multirow[t]{2}{*}{ Beta } & \multicolumn{3}{|c|}{ Subgroup ligh MCSD-score (SD-4) } \\
\hline & STATUS & ETINOABC & ETHNO \\
\hline ETINOABC & $-.107(-1.118)$ & \multirow[b]{5}{*}{1.000} & \multirow{5}{*}{1.000} \\
\hline ETHNO & $-.003(-.066)$ & & \\
\hline COMPET & $-.104(-1.885)$ & & \\
\hline ATTITUDE & & & \\
\hline \multirow{2}{*}{ NORM } & & & \\
\hline & ISTATUS & & \\
\hline \multirow[t]{2}{*}{ NORM } & $-.079(-.750)$ & & \\
\hline & COMPET & ATTITUDE & NORM \\
\hline \multirow{2}{*}{$\begin{array}{l}\text { ATTITUDE } \\
\text { CONTACT }\end{array}$} & $-.541(-1.604)$ & \multirow[b]{2}{*}{$.393(1.337)$} & \multirow[b]{2}{*}{$-.403(-2.723)$} \\
\hline & & & \\
\hline \multirow[t]{2}{*}{$\Psi$} & \multicolumn{3}{|c|}{ Subgroup low MCSD-score (SD-1) } \\
\hline & ETIINOABC & ETHINO & COMPET \\
\hline ETHNOABC & $.670(2.408)$ & & \\
\hline ETIINO & $.423(3.062)$ & $.387(3.797)$ & \\
\hline COMPET & $.653(2.986)$ & $.461(3.610)$ & $1.070(4.036)$ \\
\hline \multirow[t]{2}{*}{ ISTATUS } & & $-.323(-2.628)$ & $-.323(-2.030)$ \\
\hline & ATT./NORM & CONTACT & ISTATUS \\
\hline CONTACT & & $.512(3.832)$ & \\
\hline ISTATUS & & & $1.994(3.808)$ \\
\hline$\Psi$ & \multicolumn{3}{|c|}{ Subgroup high MCSD-score (SD-4) } \\
\hline & ETINOABC & ETHNO & COMPET \\
\hline ETIINOABC & $.567(2.641)$ & & \\
\hline ETIINO & $.229(2.338)$ & $.232(2.704)$ & \\
\hline COMPET & $.278(2.109)$ & $.264(2.405)$ & $.719(2.952)$ \\
\hline \multirow[t]{2}{*}{ ISTATUS } & & $.079(.493)$ & $.850(2.632)$ \\
\hline & ATT./NORM & CONTACT & ISTATUS \\
\hline $\begin{array}{l}\text { CONTACT } \\
\text { ISTATUS }\end{array}$ & & $.270(3.679)$ & $3.710(4.000)$ \\
\hline
\end{tabular}

Coefficients varying over the groups are presented in boldfaced type.

The t-values are in parentheses.

between IAGE and COMPET doesn't lead to an $\chi^{2}$-improvement (model variant 7 in Table 3).

The fit indices of the accepted model variant 6 have similar values $\left(G F I_{1}=\right.$ 0.819 and $G F I_{2}=0.812$ ). The reasons for the low values of the fit indices are the same as in the model with interviewer status. 
Table 3. Sequence of model testing in the multiple group comparisons (model with IAGE)

\begin{tabular}{|c|c|c|c|c|}
\hline & \multicolumn{2}{|c|}{ Total Fit } & \multicolumn{2}{|c|}{ Fit of the subgroups } \\
\hline Type of models & $x^{2}$ & $\mathrm{df}$ & $\overline{G F I_{1}}$ & $G F I_{2}$ \\
\hline $1: L Y=I N B E=I N G A=I N$ & 142.45 & 84 & .703 & .757 \\
\hline $\begin{array}{l}\text { 2: } L Y=I N B E=P S G A=I N \\
\text { NEQ: IAGE - NORM }\end{array}$ & 142.04 & 83 & .708 & .757 \\
\hline $\begin{array}{l}\text { 3: LY }=I N \text { BE }=I N \text { GA }=\text { PS } \\
\text { NEQ: STATUS - ETHNOABC }\end{array}$ & 137.49 & 83 & .715 & .764 \\
\hline $\begin{array}{l}\text { 4: LY }=\text { IN BE }=\text { PS GA }=\text { PS } \\
\text { NEQ: STATUS - ETHNOABC } \\
\text { NEQ: STATUS - ETHNO }\end{array}$ & 136.50 & 82 & .726 & .766 \\
\hline $\begin{array}{l}\text { 5: LY }=\text { IN BE }=\text { PS GA=PS } \\
\text { NEQ: STATUS - ETHNOABC } \\
\text { NEQ: STATUS - ETHNO } \\
\text { RES: V214 - Ethnoa }\end{array}$ & 119.28 & 80 & .785 & .791 \\
\hline $\begin{array}{l}\text { 6: LY }=I N \text { BE }=\text { PS GA }=\text { PS } \\
\text { NEQ: STATUS - ETHNOABC } \\
\text { NEQ: STATUS - ETHNO } \\
\text { RES: V214 - Ethnoa } \\
\text { RES: V114 - V203 } \\
\text { RES: V121 - V203 }\end{array}$ & 102.50 & 76 & .811 & .814 \\
\hline $\begin{array}{l}\text { 7: LY }=\mathrm{IN} \text { BE }=\mathrm{PS} \text { GA }=\overline{\mathrm{PS}} \\
\text { NEQ: STATUS - ETHNOABC } \\
\text { NEQ: STATUS - ETHNO } \\
\text { RES: V214 - Ethnoa } \\
\text { RES: V114 - V203 } \\
\text { RES: V121 - V203 } \\
\text { RES: IAGE - COMPET }\end{array}$ & 101.20 & 74 & .819 & .812 \\
\hline
\end{tabular}

PS = Matrices BEta, GAmma and Lambda $Y$ have the same causal structure but different coefficients across groups.

IN = Matrices BEta, GAmma and Lambda $Y$ have the same causal structure and identical coefficients across groups.

$\mathrm{NEQ}=$ Not EQual means that the numerical relation between two constructs may differ across groups.

RES $=$ RESidual Covariances between constructs or between measured variables may differ across groups.

For both groups there are no greater deviations (values in the matrix Normalized Residuals $\geq 2.0$ ) between empirical and estimated covariances.

Interpretations of the results of the accepted model variant 6 will focus on the relation between IAGE and constructs of the theory and their differences over the groups. The results of Table 4 show that there is no significant influence of interviewer age on subjective norm in both groups (0.014). This 
means also that there is no influence from IAGE via NORM on the behavior construct CONTACT. But the results show certain influences from IAGE on the attitude construct ETHNO (cf. Table 4). For both groups there are positive residual covariances between IAGE and ETHNO, non-significant (1.004) in the first group (low MCSD-score) significant (1.509) in the second group (high MCSD-score). This means that respondents adjust their response behavior in accordance with the age of the interviewer: the higher the age of the interviewer, the higher is the ethnocentrism of the respondent. But the relation is significant only for subjects for whom behaving in a socially desirable manner means behaving with hostility to foreigners.

\subsection{Comparison of explained variances of the models}

Taken as a whole, the tested models have been proved. Relations between the method theory (interviewer status and interviewer age) and subjective norm have not been confirmed. Multiple group comparisons according to social desirability (low and high MCSD-scores) have not been shown any stable and significant differences of the effect of interviewer variables on the behavior construct (CONTACT) via the subjective norm. The lack of direct measurements of constructs NORM and ATTITUDE are one of the disadvantages of the models. The relevance of the method theory is illustrated in two main results:

1. The interviewer constructs ISTATUS and IAGE covary with the attitude constructs COMPET and ETHNO.

2. The covariations between interviewer constructs and attitude constructs differ significantly in level and direction between the subgroups (cf. Tables 2 and 4) divided by high and low social desirability.

In addition to the results reported in the last sections, an overview of the explained variances in the endogenous construct CONTACT for all tested models shows that the extension of the substantive theory with a method theory can raise the explained variance (cf. Table 5).

In one case the explained variance of the construct CONTACT increases from 0.178 (model without interviewer constructs) to 0.214 (model with interviewer status), in the other, there is no increase of the explained variance ( 0.176 for the model with interviewer age).

For the subgroup analysis there are similar tendencies. The explained variance increases for the first group comparison from 0.178 (model without interviewer constructs) to 0.284 (model with interviewer status, subgroup low MCSD-score) and 0.266 (model with interviewer status, subgroup high MCSD-score). For the second group comparison the explained variance 
Table 4. Variant 6 (structural coefficients)

\begin{tabular}{|c|c|c|c|}
\hline Beta & \multicolumn{3}{|c|}{ Subgroup low MCSD-score (SD-1) } \\
\hline & STATUS & ETHNOABC & ETHNO \\
\hline ETHNOABC & $-.363(-3.619)$ & \multirow[b]{5}{*}{1.000} & \multirow[b]{4}{*}{1.000} \\
\hline ETHNO & $-.003(-.047)$ & & \\
\hline COMPET & $-.077(-.922)$ & & \\
\hline ATTITUDE & & & \\
\hline NORM & IAGE & & \\
\hline \multirow[t]{2}{*}{ NORM } & $.014(.899)$ & & \\
\hline & COMPET & ATTITUDE & NORM \\
\hline $\begin{array}{l}\text { ATTITUDE } \\
\text { CONTACT }\end{array}$ & $-.319(-1.517)$ & $.628(1.792)$ & $-.537(-2.872)$ \\
\hline \multirow[t]{2}{*}{ Beta } & \multicolumn{3}{|c|}{ Subgroup high MCSD-score (SD-4) } \\
\hline & STATUS & ETIINOABC & ETHNO \\
\hline ETIINOABC & $-.130(-1.320)$ & & \\
\hline ETIINO & $-.049(-.094)$ & & \\
\hline COMPET & $-.077(-.922)$ & & \\
\hline ATTITUDE & & & 1.000 \\
\hline \multirow[t]{2}{*}{ NORM } & & 1.000 & \\
\hline & IAGE & & \\
\hline \multirow[t]{2}{*}{ NORM } & $.014(.899)$ & & \\
\hline & COMPET & ATTITUDE & NORM \\
\hline $\begin{array}{l}\text { ATTITUDE } \\
\text { CONTACT } \\
\end{array}$ & \multicolumn{2}{|r|}{$.628(1.792)$} & $-.537(-2.872)$ \\
\hline \multirow[t]{2}{*}{$\Psi$} & \multicolumn{3}{|c|}{ Subgroup low MCSD-score (SD-1) } \\
\hline & ETIINOABC & ETIINO & COMPET \\
\hline ETINOABC & $.539(2.219)$ & & \\
\hline ETIINO & $.353(2.904)$ & $.278(3.032)$ & \\
\hline COMPET & $.608(2.935)$ & $.367(3.167)$ & $1.016(3.859)$ \\
\hline \multirow[t]{2}{*}{$\mathrm{IAGE}$} & & $1.004(1.566)$ & \\
\hline & ATT./NORM & CONTACT & IAGE \\
\hline $\begin{array}{l}\text { CONTAC' } \\
\text { IAGE }\end{array}$ & & $.508(3.777)$ & $80.161(3.808)$ \\
\hline$\Psi$ & \multicolumn{3}{|c|}{ Subgroup high MCSD-score (SD-4) } \\
\hline & ETIINOABC & ETHNO & COMPET \\
\hline ETIINOABC & $.474(2.418)$ & & \\
\hline ETINO & $.179(2.203)$ & $.197(2.676)$ & \\
\hline COMPET & $.281(2.007)$ & $.243(2.335)$ & $.721(2.643)$ \\
\hline \multirow[t]{2}{*}{ IAGE } & & $1.509(1.927)$ & \\
\hline & ATT./NORM & CONTACT & IAGE \\
\hline $\begin{array}{l}\text { CON'TACT } \\
\text { IAGE }\end{array}$ & & $.242(3.451)$ & $124,445(4.000)$ \\
\hline
\end{tabular}

Coefficients varying over the groups are presented in boldfaced type.

The $t$-values are in parentheses.

increases from 0.178 (model without interviewer constructs) to 0.278 (model with interviewer age, subgroup low MCSD-score) and 0.331 (model with interviewer age, subgroup high MCSD-score).

There are two effects of interviewer characteristics and social desirability: 
Table 5. Explained variances for the construct CONTACT

\begin{tabular}{|l|c|}
\hline & Explained variance \\
\hline $\begin{array}{l}\text { Baseline-model } \\
\text { no method theory } \\
\text { (total sample) }\end{array}$ & .178 \\
\hline $\begin{array}{l}\text { Model with } \\
\text { ISTATUS } \\
\text { (total sample) }\end{array}$ & .214 \\
\hline $\begin{array}{l}\text { Model with } \\
\text { IAGE } \\
\text { (total sample) }\end{array}$ & .176 \\
\hline $\begin{array}{l}\text { Model with } \\
\text { ISTATUS } \\
\text { (subgroup SD-1) }\end{array}$ & .284 \\
\hline $\begin{array}{l}\text { Model with } \\
\text { ISTATUS } \\
\text { (subgroup SD-4) }\end{array}$ & .266 \\
\hline $\begin{array}{l}\text { Model with } \\
\text { IAGE } \\
\text { (subgroup SD-1) }\end{array}$ & .278 \\
\hline $\begin{array}{l}\text { Model with } \\
\text { IAGE } \\
\text { (subgroup SD-4) }\end{array}$ & \\
\hline
\end{tabular}

biased coefficients because of omitted variables and the underestimation of explained variances. By the way we modelled the data we could show at which degree of social desirability and amount of interviewer influences biased coefficients and underestimation of explained variances in the structural models occurred. The results in Table 5 indicate a higher amount of explained variances for the models with the method theory.

\section{Summary and conclusion}

Let us now summarize the main results and draw some conclusions:

1. Theory: Groves \& Magilavy (1988) have complained about a lack of theory in studies of interviewer effects, a criticism we think justified. We have used the theory of reasoned action (Ajzen \& Fishbein 1980) to 
perform this task. Such a theory was able to show under which conditions of perceived expected utility and norms intentions and behaviors of respondents may change. In an overall view the tested models have been proved and we have furnished explanatory sketches showing why age and status of interviewers may change latent and therefore also reported attitudes and behavior of respondents. In further research the stability of the amount of additional variance remains to be tested. Also subject to further testing is the relationship between the interviewer characteristics and the constructs of our theory, especially attitudes toward behavior and norms.

2. Method: In contrast to many researchers we have not used cross-tabulations, simple correlation coefficients or intraclass correlation coefficients in our analyses. Instead, we have combined structural equation models with latent variables and a multivariate approach to test the effect of interviewer characteristics and social desirability. We have demonstrated how the specification and testing of such models can be performed and that only coefficients of the structural model (point estimates and explained variances) are affected. This will also change the reported attitudes and behaviors via the measurement model. Interestingly enough the factor loadings of the items themselves stayed invariant for the subgroups.

We want to add a note of caution: As our sample size is small, our findings need a replication. Furthermore one has to take into account that our theoretical constructs (NORM and ATTITUDE) have no residuals because of identification restrictions. The coefficients might change when we would allow for non-zero residuals for these two constructs. In further studies one should corroborate these findings as well as considering the means of the observed and latent variables.

3. Social desirability and interviewer effects: By simultaneously recording and testing social desirability and interviewer effects in multiple group structural equation models it was possible to test the combination of both effects.

In the future more studies will be needed testing these combined effects as well as their stability. To systematize the ongoing research one would have to examine a list of relevant interviewer characteristics for varying topics which show significant influences on reported attitudes and behavior.

4. Design: In our experimental design it was possible to vary some characteristics of the interviewers. Such a procedure is frequently not possible in empirical research projects. However, to study the problems of interviewer effects and social desirability the following measures could be taken with little additional costs: 
(a) Use of a short scale of social desirability

(b) Record the most relevant demographic characteristics of interviewers (gender, age, education, income, professional status, interviewer experience) and some central attitudes which are relevant in the ongoing research.

By adding this information to the data of the interviewees one can test models as we have done in this paper. Such a procedure has been used in the German General Social Survey 1980 (ALLBUS, cf. Schanz \& Schmidt 1984) and 1990. By comparing results over a wide variety of studies it would become clearer to what extent interviewer effects and social desirability bias the coefficients of our tested models and reported frequency of expressions of behavior, opinions and attitudes. Furthermore, one could correct for these non-random measurement errors.

\section{Notes}

1. MIMIC is the short form for "Multiple Indicators Multiple Causes" (cf. Jöreskog \& Sörbom 1988: 142ff; Bollen 1989: 331).

2. Ajzen (1988: 49) shows the summing up in columns of single-act criteria to multiple-act criteria and the summing up of the same to tendencies of behavior.

3. Here we try to adopt our own consistent system of notations since those used by Ajzen and Fishbein tend to vary.

4. Concerning the origin of this theoretical approach cf. Dulany's "theory of proposition control" (1961).

5. In our opinion the normative factor is also a product of expectancies (as normative beliefs) and values (as motivation to consent reference individuals), while Ajzen and Fishbein state this only for the factor attitude.

6. Motivation for conformity means:

1. motivation to submit to the reference group and

2. motivation to engage in specific expectancies of the reference group.

7. The distinction of $I$ and others can be proved by the research of Schuessler (1982), in which dimensions in "Social Life Feeling Scales" differentiate in item formulation between "I" and "Most People". In the research cited above, "attitudes about me and others in society" have been questioned, which corresponds exactly to the categorization according to Fishbein. In contrast to this, Ajzen and Fishbein say that empirical data have proved that the inclusion of personal normative ideas does not contribute to the understanding of the determinants of behavior intentions. They also cite problems of operationalization which, in our opinion, can be solved partly through the use of item formulations in the way Schuessler used them (cf. Ajzen \& Fishbein 1978: 408, footnote 7).

8. From an empirical point of view it is possible that type 2 and 3 are equally important and the formula cited above can be reduced by one term. We want to emphasize the distinction in order to clarify the meaning of this approach for the measurement theory and to distinguish the interview situation from everyday situations.

9. Essen-Holsterhausen is a district where only few foreigners live, whereas Essen-AltenessenNord is a district where many foreigners live. The different numbers of foreigners was meant to guarantee variance in the constructs ethnocentrism and primary milieu. 
10. Relations between these constructs have been estimated with residual correlation that can be interpreted like structural coefficients.

11. In multiple-group comparisons information about the different grades of variability of the items are necessary so that it is always a covariance matrix which must be used as input matrix.

12. To set free means that the respective coefficients can be estimated differently beyond all groups and that the structure of the model, however, remains.

13. In multiple-group comparisons the $\chi^{2}$-value indicate the overall fit of the model beyond the groups, whereas the GFI-Values (Goodness-of-Fit-Index) indicate the adjustment of the model to the respective subgroup.

14. Q-Ratio is the ratio of the $\chi^{2}$-difference to df-difference.

\section{References}

Ajzen, I. (1988). Attitudes, Personality and Behavior, Milton Keynes.

Ajzen, I. and M. Fishbein (1977). Attitude - Behavior Relations: A Theoretical Analysis and Review of Empirical Research, Psychological Bulletin 84: 888-918.

Ajzen, I. and M. Fishbein (1978). Einstellungs- und normative Variablen als Prädiktoren für spezifische Verhaltensweisen. In W. Stroebe (ed.), Sozialpsychologie. Band 1, Darmstadt, pp. 404-443.

Ajzen, I. and M. Fishbein (1980). Understanding Attitudes and Predicting Social Behavior, New Jersey.

Biemer, P.P., R.M. Groves, L.E. Lyberg, N.A. Mathiowetz, and S. Sudman (eds.) (1991). Measurement Errors in Surveys, New York.

Blalock, H.M. (1969). Multiple Indicators and the Causal Approach to Measurement Error, American Journal of Sociology 75: 264-272.

Bollen, K.A. (1989). Structural Equations with Latent Variables. New York.

Bynner, J. (1990). Reliability and Validity Appraisal through Structural Equation Models, Bulletin de Methodologie Sociologique 28: 41-55.

Cannell, C.F. and R.L. Kahn (1968). Interviewing. In Gardner, L. and E. Aronson (eds.), Handbook of Social Psychology. Massachussets, pp. 526-595.

Carmines, E. and R.A. Zeller (1980). Reliability and Validity Assessment, Beverley Hills.

Costner, H.L. (1969). Theory, Deduction, and Rules of Correspondence, American Journal of Sociology 75: 245-263.

Crowne, D.P. and D. Marlowe (1960). A New Scale of Social Desirability Independent of Psychopathology, Journal of Consulting Psychology 24: 349-354.

Dulany, D.E. (1961). Hypotheses and Habits in Verbal "Operant Conditioning", Journal of Abnormal and Social Psychology 63: 251-263.

Esser, H., P.B. Hill and G. von Oepen (1983). Sozialökologische Bedingungen der Eingliederung ausländischer Arbeitnehmer im Ruhrgebiet (am Beispiel der Stadt Duisburg). Teil 2: Die deutsche Bevölkerung und ihr Verhältnis zu den ausländischen Arbeitnehmern, Essen.

Esser, H., P.B. Hill, E. Korte, I. Kurosch and R. Schnell (1986). Kulturelle und ethnische Identität bei Arbeitsmigranten im interkontextuellen und intergenerationalen Vergleich, Essen.

Fishbein, M. (1967). Attitude and the Prediction of Behavior. In M. Fishbein (ed.), Readings in Attitude Theory and Measurement, New York, pp. 477-492.

Fuller, W.A. (1987). Measurement Error Models, New York.

Groves, R.M. and L.J. Magilavy (1988). Measuring and Explaining Interviewer Effects in Centralized Telephone Surveys. In E. Singer and S. Presser (eds.), Survey Research Methods, Chicago, pp. 288-303.

Graff, J. and P. Schmidt (1982). A General Model for Decomposition of Effects. In K.G. Jöreskog and H. Wold (eds.), Systems under Indirect Observation, Amsterdam, pp. 131-148. 
Hermann, D. and F. Streng (1986). Das Dunkelfeld der Befragung, Kölner Zeitschrift für Soziologie und Sozialpsychologie 38: 337-351.

Hyman, H. et al. (1954). Interviewing in Social Research, Chicago.

Jöreskog, K.G. and D. Sörbom (1988). LISREL VII: A Guide to the Program and Applications, Chicago.

Kahn, R.L. and C.F. Cannell (1957). The Dynamics of Interviewing, New York.

Kish, L. (1962). Studies of Interviewer Variance for Attitudinal Variables, Journal of the American Statistical Association 57: 92-115.

Krauth, C. and R. Porst (1984). Sozioökonomische Determinanten von Einstellungen zu Gastarbeitern. In K.U. Mayer and P. Schmidt (eds.), Allgemeine Bevölkerungsumfrage der Sozialwissenschaften, Frankfurt, pp. 233-226.

Reinecke, J. (1985). Kausalanalytischer Erklärungsversuch von Verzerrungen durch soziale Erwünschtheit: Die Schätzung von Kern-, Meß- und Methodentheorie, Zeitschrift für Soziologie 14: 386-399.

Reinecke, J. (1991a). Interviewereffekte und Soziale Erwünschtheit: Theorie, Modell und empirische Ergebnisse, Journal für Sozialforschung 31: 293-320.

Reinecke, J. (1991b). Interviewer- und Befragtenverhalten: Theoretische Ansätze und methodische Konzepte, Opladen.

Rindskopf, D.M. (1984). Using phantom and imaginary latent variables to parameterize constraints in linear structural models, Psychometrika 49:37-47.

Saris, W.E. and F.M. Andrews (1991). Evaluation of Measurement Instruments Using a Structural Modeling Approach. In P.P. Biemer, R.M. Groves, L.E. Lyberg, N.A. Mathiowetz, and S. Sudman (eds.), Measurement Errors in Surveys, New York, pp. 575-597.

Saris, W.E. and A. van Meures (1990). Evaluation of Measurement Instruments by Meta-Analyses of Multitrait-Multimethod Studies, Amsterdam.

Schanz, V. and P. Schmidt (1984). Interviewereffekte im Nationalen Survey. In K.U. Mayer and P. Schmidt (eds.), Allgemeine Bevölkerungsumfrage der Sozialwissenschaften, Frankfurt, pp. $72-113$.

Schuessler, K. (1982), Measuring Social Life Feelings, San Francisco.

Sobel, M.E. and G.W. Bohrnstedt (1985). Use of Null Models in Evaluating the Fit of Covariance Structure Models, Sociological Methodology, 152-178.

Sörbom, D. (1979). A General Method for Studying Differences in Factor Means and Factor Structure between Groups. In K.G. Jöreskog and D. Sörbom (eds.), Advances in Factor Analysis and Structural Equation Models, Cambridge, pp. 207-217.

Sörbom, D. (1982). Structural Equation Models with Structured Means. In Jöreskog, K.G. and H. Wold (eds.), Systems under Indirect Observations, Amsterdam, pp. 183-195.

ZUMA-Scalehandbook (1983). Part 1 to 3. Bonn. 